\title{
High Nitrogen Containing Ni-free Austenitic Steels for Medical Applications
}

\author{
Joachim MENZEL, Walter KIRSCHNER and Gerald STEIN \\ VSG Energie- und Schmiedetechnik GmbH, Westendstr. 15, 45143 Essen, Germany.
}

(Received on September 29, 1995; accepted in final form on January 18, 1996)

\begin{abstract}
New nickel-free CrMnMo austenites with up to $1 \%$ nitrogen developed by VSG exhibit properties which correspond particularly well to medical engineering requirements. The combination of strength, toughness, corrosion resistance, wear resistance and cost-efficiency which these alloys display is not attained by any other material.
\end{abstract}

KEY WORDS: nickel allergy; alloy development; biocompatible austenitic steels.

\section{Introduction}

Allergies figure among the illnesses which are undergoing a dramatic increase ${ }^{1)}$ (Fig. 1). In this connection nickel ions are the most common contact allergen. Statistics show that today between 10 and $20 \%$ of women and $2 \%$ of the male population are affected. A nickel allergy triggers visible inflammatory reactions on the skin and mucous membranes in the form of red patches or, in the worst case, eczema.

As well as other nickel-containing alloys the conventional 18/10 CrNi steels in particular are suspected of triggering nickel allergies on contact with the human body. A particularly contentious area is their use in surgical and dental prosthetics as although these alloys are resistant to general surface corrosion they are not resistant to local forms of corrosion such as pitting, crevice corrosion and stress corrosion. This increases both the release of potentially reactive nickel ions and also the risk of cracking. Alternative materials such as titanium and cobalt alloys to a large extent also contain considerable amounts of nickel and are, without exception, extremely expensive.

On the basis of the problem described above legislation has been introduced in some countries of the European Community and in the U.S.A. in order to restrict the use of nickel-containing materials for applications on and in the human body.

\section{Objective}

An important and urgent task of material research is to develop economic alternatives to the nickel-containing austenites which meet the following requirements:

- High strength and good toughness in order to ensure shape stability and protection against breakage with the associated risk of injury.
- Sufficient bending fatigue strength in order to guarantee the necessary processing properties and protection against fatigue fracture.

- Good corrosion- and wear-resistance in order to keep the release of harmful alloy components to a minimum and to prevent fractures arising through local corrosion.

- Surface finish.

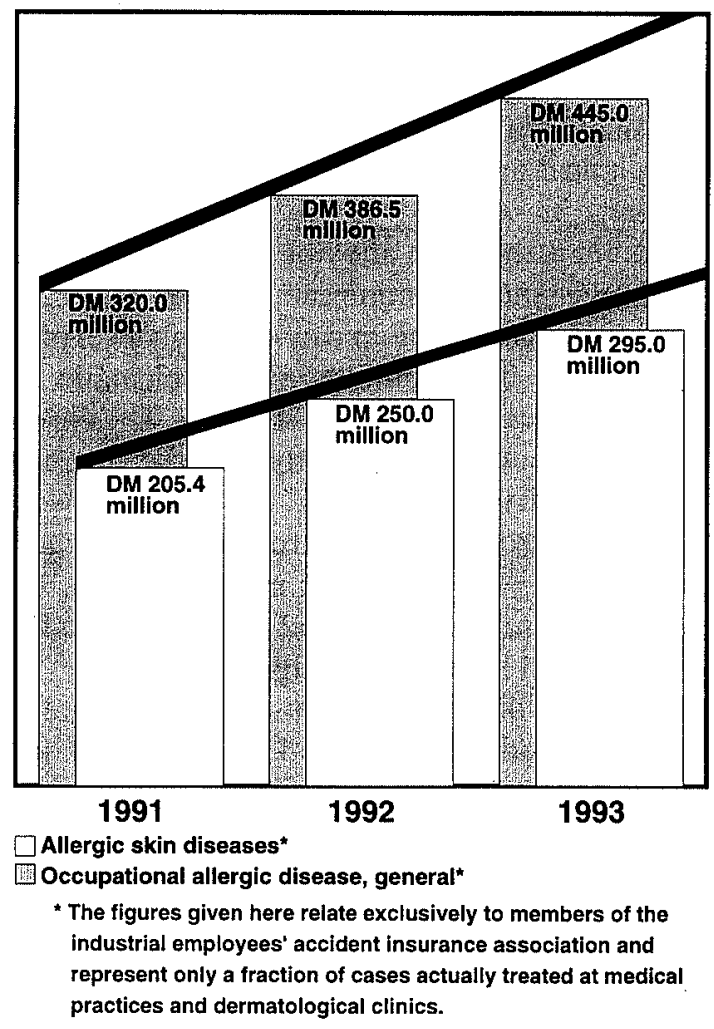

Fig. 1. As the example of the industrial employees' accident insurance association shows, the expenditure for illnesses caused specifically by skin allergies is increasing sharply. 
- Availability and price.

\section{Development of a New Generation of Biocompatible Materials}

On the basis of the requirements described above the following parameters derived for the development of a new alloy:

- Nickel-free.

- Highest possible strength, also in solution-annealed condition, through interstitial and substitutional solid solution hardening, and through the finest-grained recrystallization microstructure possible. Precipitation hardening is not suitable owing to the loss of toughness and corrosion-resistance.

- High resistance to both stress corrosion and pitting (resistance to pitting: $\mathrm{PRE} \cong \% \mathrm{Cr}+3.3 \% \mathrm{Mo}+$ $25 \% \mathrm{~N})$.

- Adequate toughness over entire strength range (free from $\delta$-ferrite, $\sigma$-phase and precipitations).

- Good cold-formability and high potential for strain hardening without the formation of martensite.

- A magnetic behaviour i.e. stable austenitic microstructure.

- Very high degree of purity to make possible a high-quality surface finish (polishability) required of the final product.

The development of nickel-free austenites was based on the good experience gained with other nitrogen bearing steels. ${ }^{2,3)}$ In this connection the influence of the following alloying elements was considered and examined:

Nitrogen in solid solution enhances the hardness, strength and corrosion resistance, and causes a large potential for strain hardening and strong austenite stabilization. Since with high nitrogen contents the toughness and corrosion resistance fall drastically as a result of unavoidable $\mathrm{Cr}_{2} \mathrm{~N}$ precipitations the upper limit of the technical appropriate nitrogen content has to be determined.

Chromium is the main alloying element for corrosionresistant steels and at a minimum content of $13 \%$ leads to passivation. As chromium causes a high level of ferrite formation, very high contents are problematic on account of the necessary austenite stability. The chromium portion contributes significantly to the increase in nitrogen solubility.

Manganese also increases nitrogen solubility and assists in stabilizing the austenitic microstructure. Unlike nickel, manganese is an essential trace element for the human body and is thus biocompatible.

Molybdenum distinctly increases nitrogen solubility but primarily leads to a marked improvement in corrosion resistance properties. However, like chromium, higher molybdenum contents lead to the formation of $\delta$-ferrite and $\sigma$-phase.

Carbon has a negative influence on corrosion resistance and nitrogen solubility and should be kept to a minimum.

Nickel should be present only in traces as an impurity. A content of less than $0.2 \%$ corresponds to medical requirements.
Ni contents markedly less than $0.2 \%$ lead to considerable additional costs in the steel meltshop as only build-up heats are possible.

\section{Nitrogen Metallurgy}

In order to achieve the high nitrogen content aimed for it is possible to influence two factors which are described using Sievert's square root law (Fig. 2). According to this, nitrogen solubility depends on the one hand on the composition of the alloy and on the other on the partial pressure of the nitrogen. In Armco iron only $0.04 \% \mathrm{~N}$ can be dissolved at normal atmosphere ( 1 bar). Figure 2 shows the influence of the alloying elements on nitrogen solubility. The highly solubilitypromoting elements $\mathrm{V}, \mathrm{Nb}$ and $\mathrm{Ti}$ cannot be added in significant amounts as they are very powerful nitride formers. It immediately becomes clear, therefore, that FeCrMnMo alloys are a suitable solution. ${ }^{4}$ Figure 3 shows the typical solubility ratios for Armco iron, a $13 \%$ $\mathrm{Cr}$ steel and a $\mathrm{CrMn}$ austenite. It is clear that:

- $\mathrm{Cr}$ and Mn strongly increase solubility.

$$
\begin{aligned}
& \text { Sievert's: }[\% \mathrm{~N}]=\frac{0,0396}{f_{N}} * \sqrt{\mathrm{P}_{\mathrm{N}_{2}}} \\
& \log f_{N}=e_{N}^{c r} *[\% \mathrm{Cr}]+e_{N}^{c} *[\% \mathrm{C}]+\ldots
\end{aligned}
$$

\begin{tabular}{|c|c|}
\hline element & $\mathrm{e}_{\mathrm{N}}$ element \\
\hline $\mathrm{C}$ & +0.125 \\
\hline $\mathrm{Si}$ & +0.065 \\
\hline $\mathrm{Ni}$ & +0.01 \\
\hline $\mathrm{W}$ & -0.0015 \\
\hline $\mathrm{Mo}$ & -0.01 \\
\hline $\mathrm{Mn}$ & -0.02 \\
\hline $\mathrm{Cr}$ & -0.045 \\
\hline $\mathrm{V}$ & -0.11 \\
\hline $\mathrm{Nb}$ & -0.06 \\
\hline $\mathrm{Ti}$ & -0.053 \\
\hline
\end{tabular}

Fig. 2. Sievert's law and parameter for the calculation of the nitrogen solubility at $1600^{\circ} \mathrm{C}$.

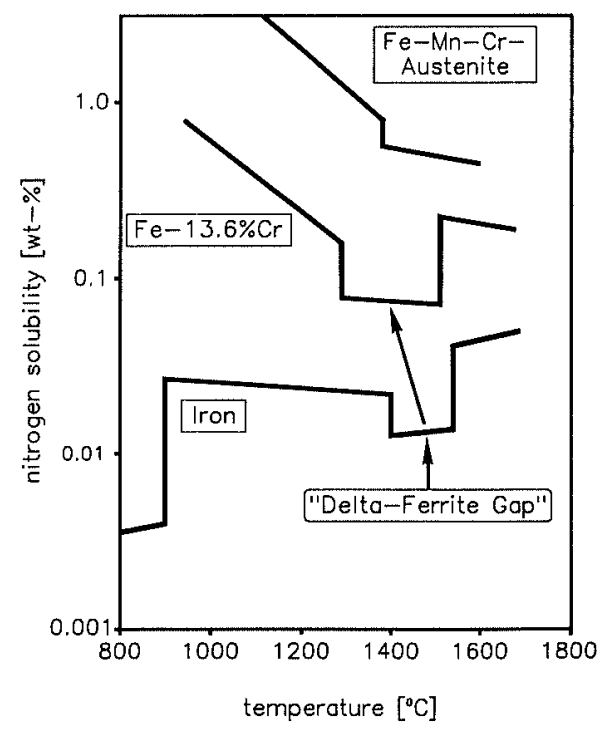

Fig. 3. N-solubility in iron and in steels at $0.1 \mathrm{MPa}$. 
- The solubility in the heat is lower than in the austenite but higher than in the $\delta$-ferrite, with the corresponding result that loss of nitrogen can occur in the solidification interval and porosity in the case of $\delta$-ferrite formation.

- The solubility in the austenite increases as the temperature decreases, which is of significance in respect of heat treatments. In this temperature range at normal atmosphere no nitrogen removal takes place. The second influential factor in determining the nitrogen content is, as mentioned above, the partial pressure of the nitrogen. As shown in Fig. 2 the nitrogen content increases by the square root of the partial pressure. For the secondary metallurgical manufacture

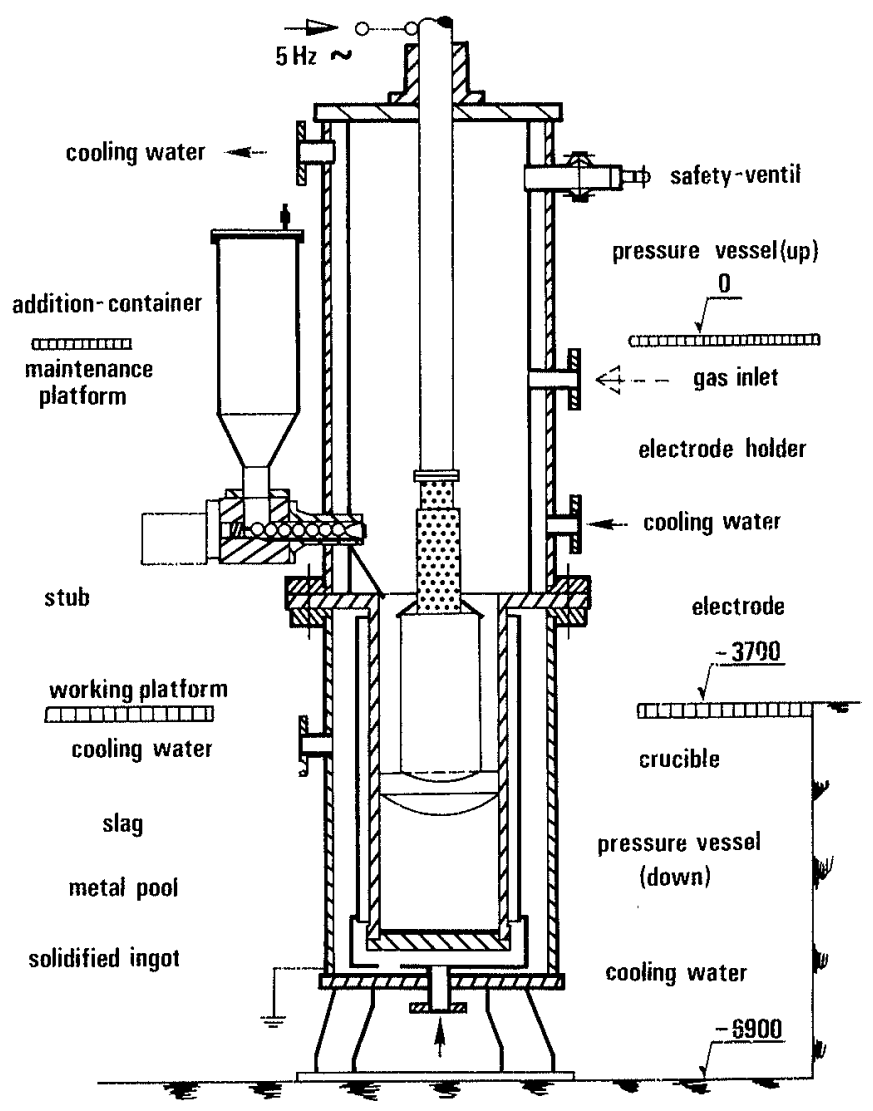

Fig. 4. Scheme of the pressure-electro-slag-remelting equipment. of steels with a high nitrogen content, melting and solidification under pressure are therefore appropriate.

VSG Energie- and Schmiedetechnik GmbH operates the world's first and to date only large-scale plant for the nitrogen alloying of metals under pressure ${ }^{5)}$ (Fig. 4). The PESR (pressurized electroslag remelting) process is the same as the ESR process but is carried out in a closed vessel under pressure. The remelting unit consists of a split pressure vessel. The lower part of the pressure vessel contains the water-cooled copper crucible, the upper part contains feeder locks for the addition of the nitrogen carrier, safety devices and the bushing for the watercooled electrode rod. The nitrogen is added continually in the form of solid nitrogen-bearing additives during the remelting process and descends through the molten slag to reach the metal phase. The pressure in the system serves solely to retain the nitrogen introduced to the pool of molten metal.

Figure 5 shows the highly austenite-forming character of the nitrogen by way of a modified Schäffler diagram. Through the addition of $1 \% \mathrm{~N}$ a purely ferritic alloy is rendered completely austenitic.

The direction taken in developing the alloy is presented schematically in Fig. 6. Owing to the opposing requirements of austenite stability and good corrosion resistance usually achieved using the ferrite-forming elements chromium and molybdenum the alloy development is always in the $\gamma$-area, along the border line of the $\gamma+\alpha$ area. Nitrogen ideally increases both austenite stability and corrosion resistance and prevents the formation of $\sigma$-phase.

\section{Precipitation Behaviour of the $\mathrm{N}$-alloyed CrMn Austenites}

The interstitial dissolution of the nitrogen and the homogeneous distribution of all the alloying elements are of decisive importance for virtually all the key properties of these steels. Depending on composition, high-alloyed nitrogen austenites can be susceptible to the formation of chromium nitrides, $\delta$-ferrite and $\sigma$-phase. As shown in Fig. 7, the microstructure is influenced by various alloying elements. What is striking is the fact that those elements which increase the formation of

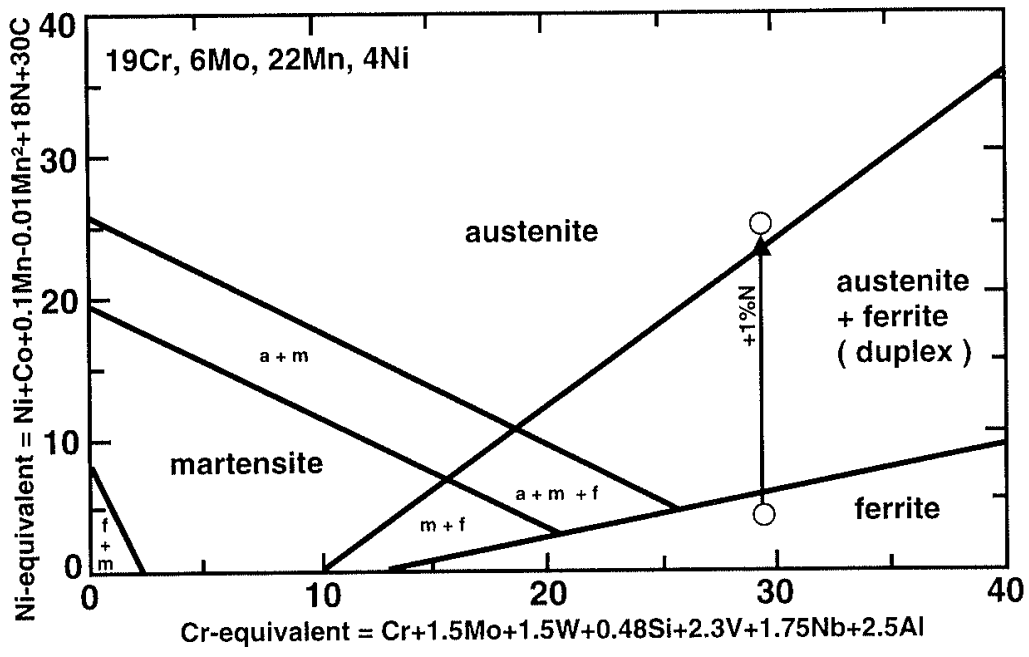

Fig. 5.

Influence of nitrogen on crystalline structure 


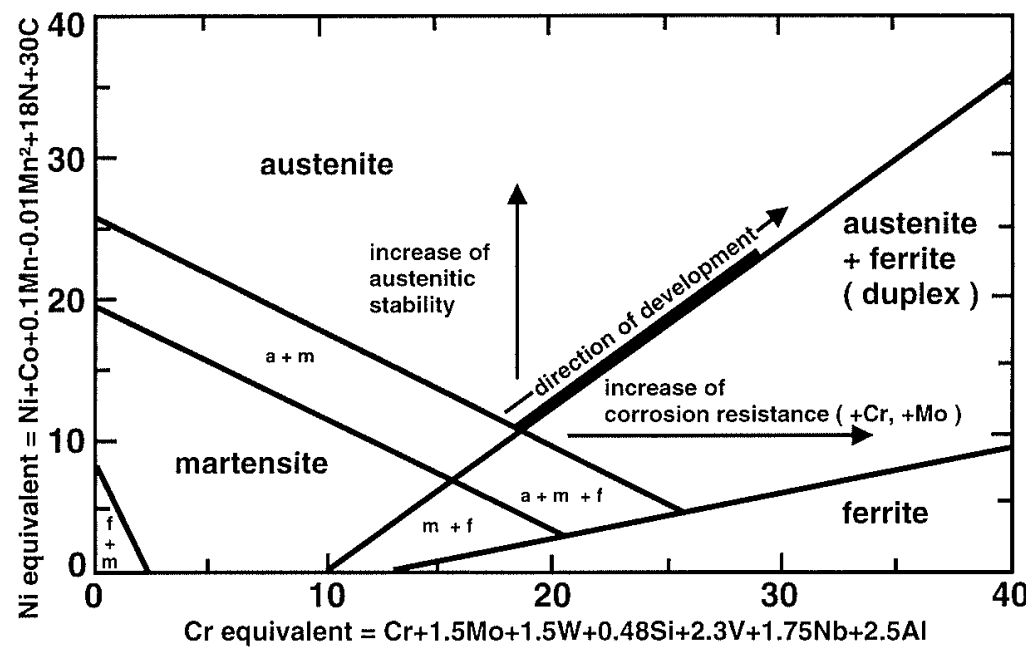

Fig. 6.

Development of biocompatible nitrogen-austen-

Cr equivalent $=\mathrm{Cr}+1.5 \mathrm{Mo}+1.5 \mathrm{~W}+0.48 \mathrm{Si}+2.3 \mathrm{~V}+1.75 \mathrm{Nb}+2.5 \mathrm{~A}$ ites.

\begin{tabular}{|l|c|c|}
\hline & $\mathrm{Cr}_{2} \mathrm{~N}$ & $\sigma$ - Phase \\
\hline $\begin{array}{l}\text { Elements, increasing } \\
\text { the precipition rate }\end{array}$ & $\begin{array}{c}\mathrm{Cr}, \mathrm{Mn}, \mathrm{Mo} \\
\mathrm{V}, \mathrm{Nb}\end{array}$ & $\begin{array}{c}\mathrm{Ni}, \mathrm{Co}, \mathrm{Cu} \\
\mathrm{C}, \mathrm{N}\end{array}$ \\
\hline $\begin{array}{l}\text { Elements, decreasing } \\
\text { the precipition rate }\end{array}$ & $\begin{array}{c}\mathrm{Ni}, \mathrm{Co}, \mathrm{Cu} \\
\mathrm{C}, \mathrm{N}\end{array}$ & $\begin{array}{c}\mathrm{Cr}, \mathrm{Mn}, \mathrm{Mo} \\
\mathrm{V}, \mathrm{Nb}\end{array}$ \\
\hline
\end{tabular}

Fig. 7. Influence of alloying elements on the precipitation behaviour of nitrogenaustenites.

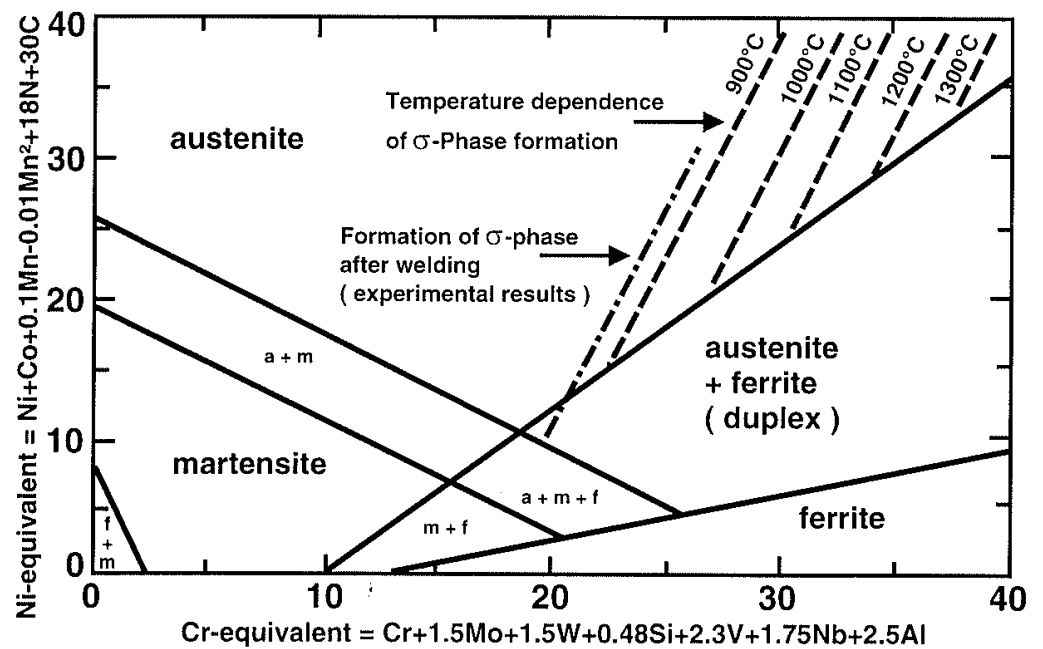

Fig. 8.

Temperature dependence of $\sigma$-phase formation.

chromium nitride precipitation reduce the formation of $\sigma$-phase and vice versa. The elements $\mathrm{N}$ and Mo have a particularly strong influence here. Figure 8 shows how the susceptibility to sigma-phase formation increases as the Mo and $\mathrm{Cr}$ contents are increased as planned. Increasing $\mathrm{N}$ contents on the other hand promote the precipitation of chromium nitrides, which, however, owing to the higher solubility are far less pronounced in the $\mathrm{CrMn}$ austenites than in the $\mathrm{CrNi}$ austenites (Fig. 9). Figure 10 gives an impression of the time scale for precipitate formation as a function of temperature and $\mathrm{N}$ content. Photomicrographs illustrate the microstructures:

Fig. 11a): Optimally solution-annealed austenitic microstructure

Fig. 11b): Austenitic microstructure with $\mathrm{Cr}_{2} \mathrm{~N}$ precipitates in the form of "nitrous pearlite," precipitated on cooling from the solution annealing temperature in the temperature range between 980 and $700^{\circ} \mathrm{C}$.

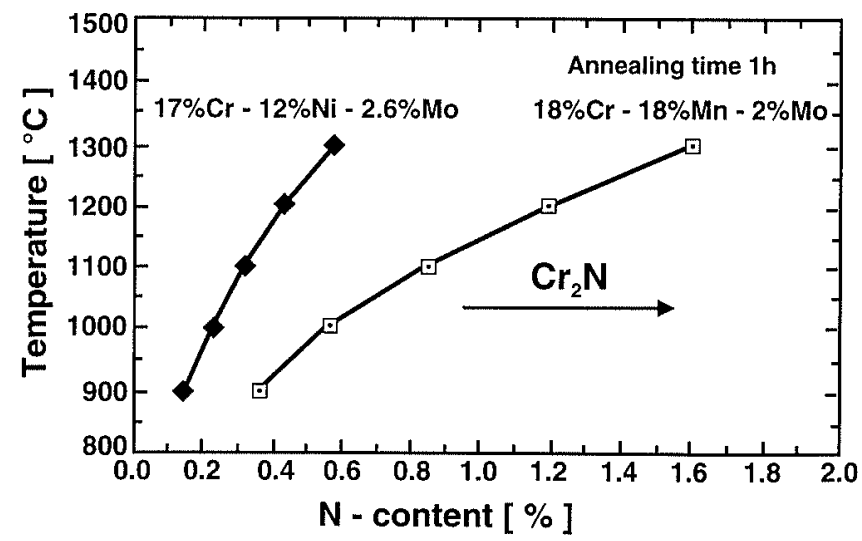

Fig. 9. Nitride formation behaviour of $\mathrm{CrNi}-$ and $\mathrm{CrMn}-$ austenites.

Possible causes: $\mathrm{N}$ content too high or cooling rate too slow

Fig. 11c): Predominantly austenitic microstructure with $\sigma$-phase. 
Possible causes: $\mathrm{N}$ content too low or $\mathrm{Cr} / \mathrm{Mo}$ content too high.

The influences of the alloying elements described above make it clear that it is only possible to attain a precipitate-free, homogeneous microstructure with a very well balanced combination. It is clear from Fig. 12 that key properties are connected to this very prerequisite. A drastic reduction in fracture toughness and corrosion resistance is linked with the occurrence of $\sigma$-phase and $\mathrm{Cr}$ nitrides. The nitrogen content limits, within which

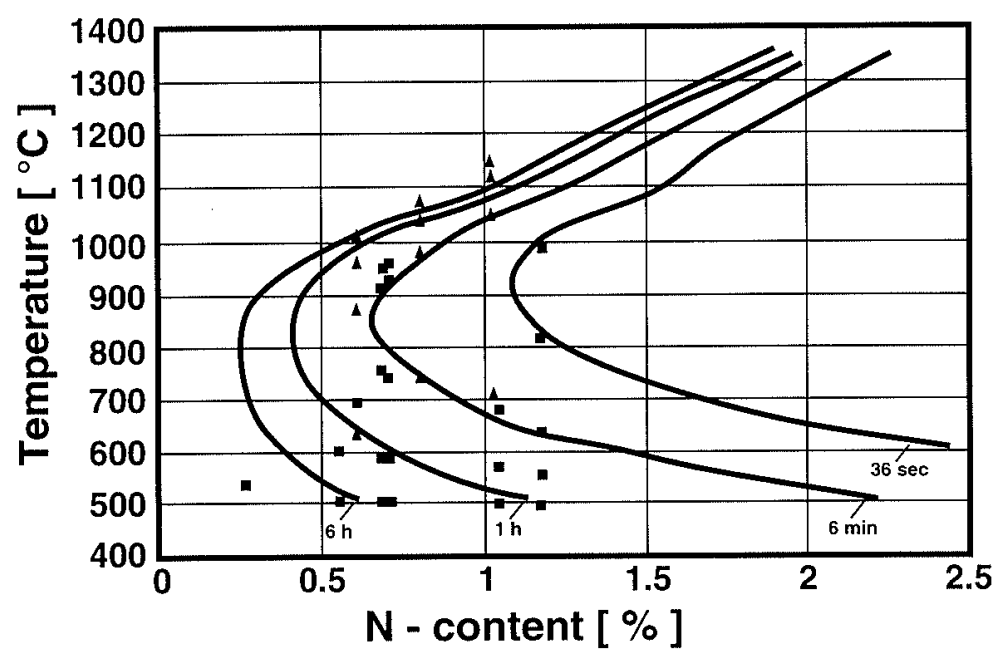

Fig. 10. After isothermal annealing nitride formation in $18 \mathrm{Cr} 18 \mathrm{Mn}$-austenites.

a)

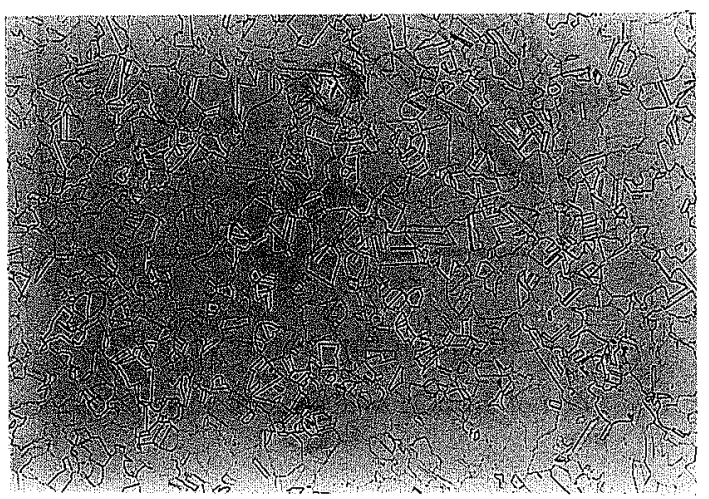

100:1

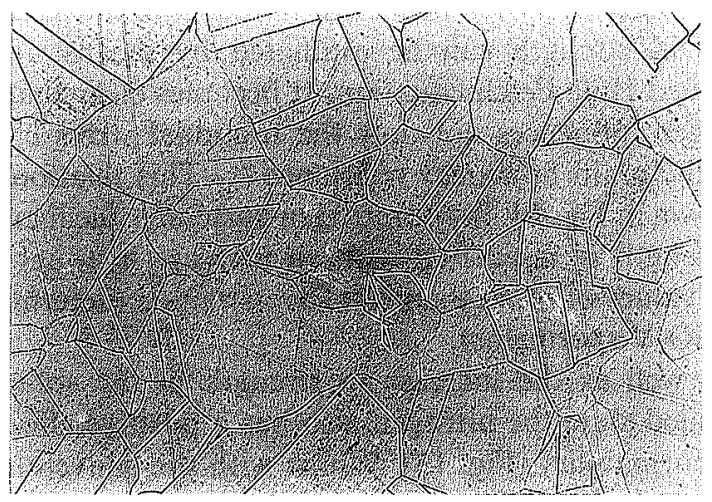

$500: 1$ b)
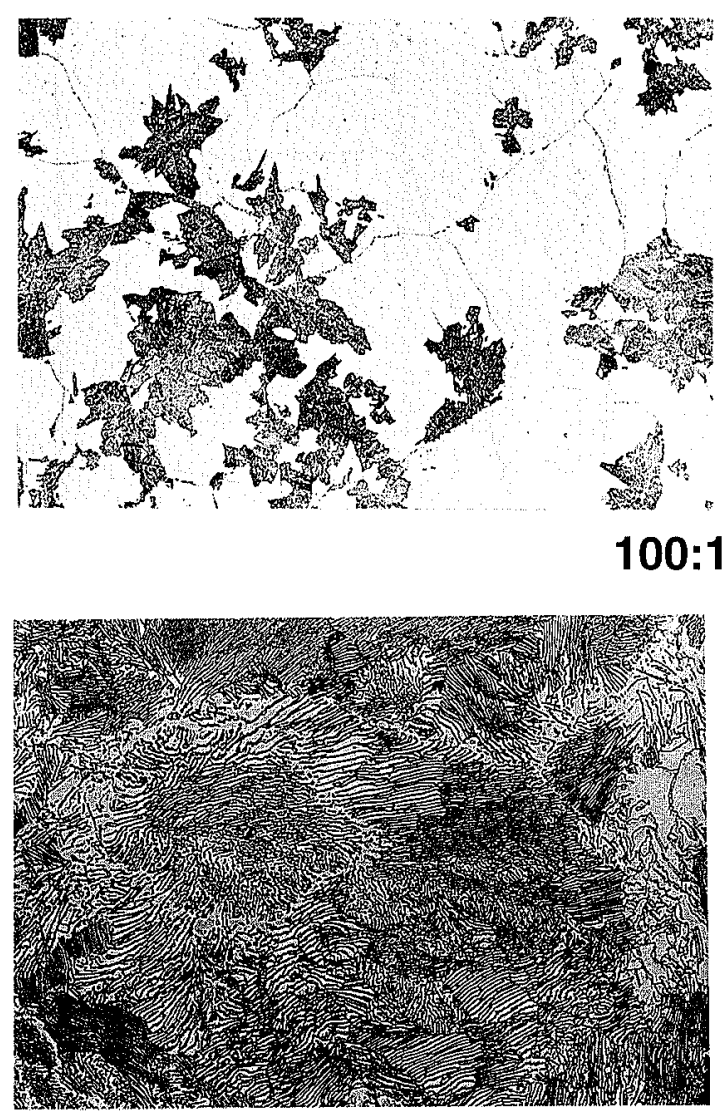

$500: 1$

c)

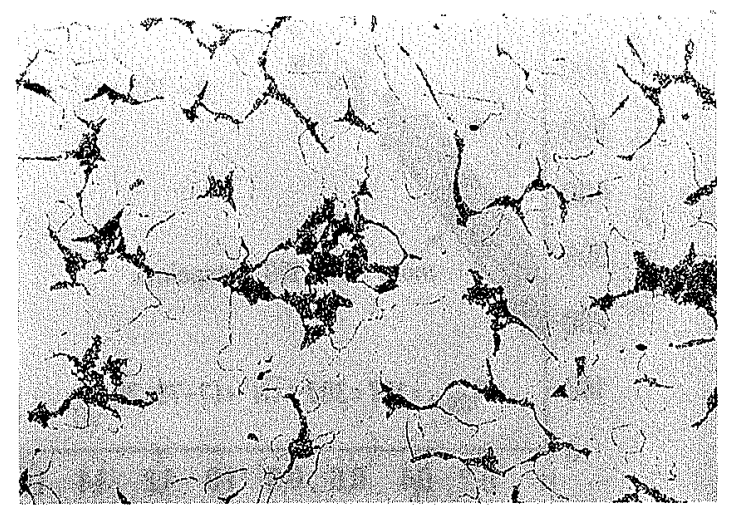

$100: 1$

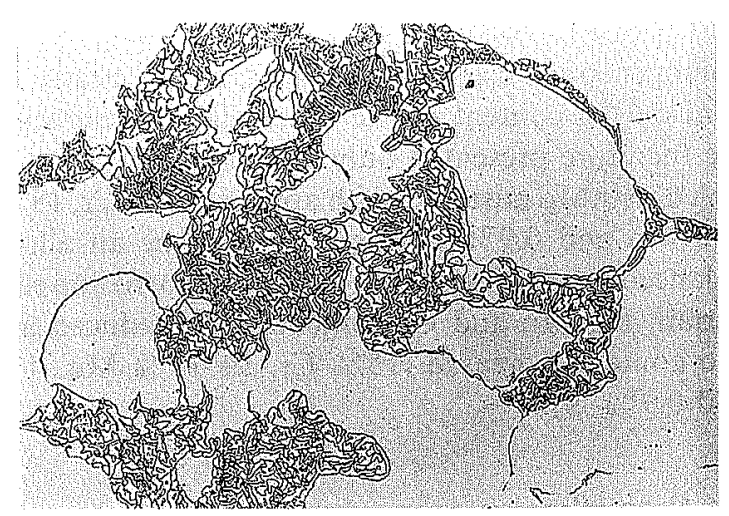

500:1

Fig. 11.

a) Solution heat treated

b) Nitrogen pearlite

c) Formation of $\sigma$-phase. 


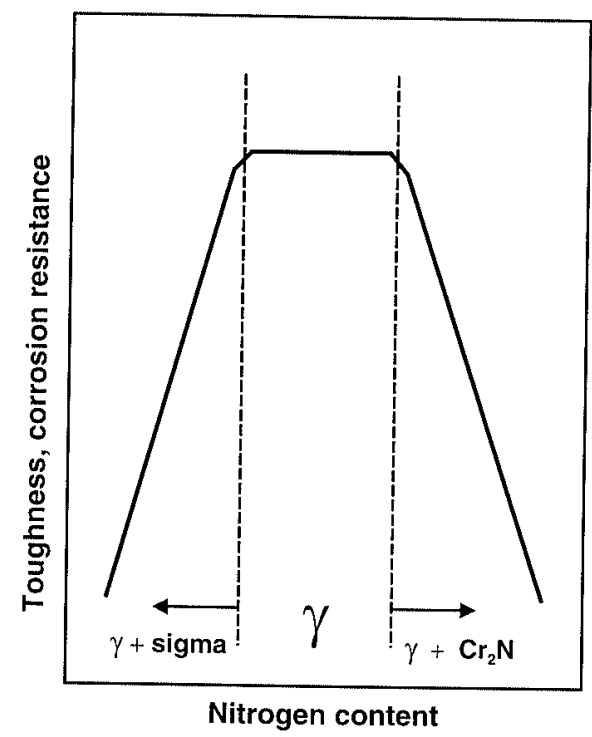

Fig. 12. Materials properties, depending on the precipitation state.

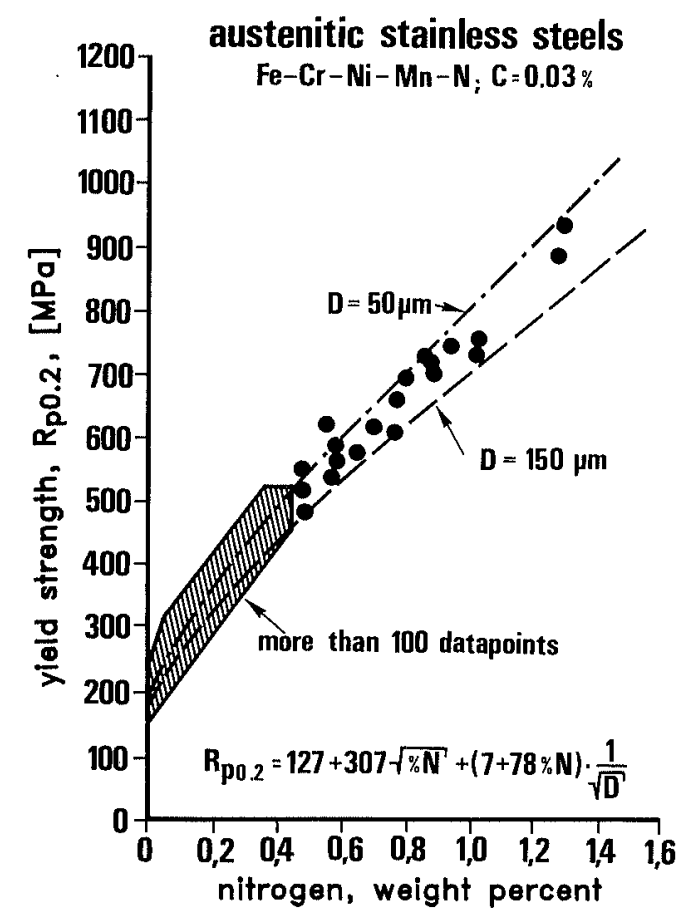

Fig. 13. Effect of nitrogen in solid solution.

homogeneous austenite is present, are of course dependent on the content of the other alloying elements and are therefore presented only schematically.

A CrMnMo austenite with approx. $18 \% \mathrm{Cr}, 18 \% \mathrm{Mn}$, $2 \%$ Mo and $0.9 \% \mathrm{~N}$ has proved to be an alloy with balanced properties. For an even more corrosion resistant variant the $\mathrm{Mn}$ and $\mathrm{Cr}$ contents were reduced and the Mo content increased $(15 \% \mathrm{Cr}, 10-15 \% \mathrm{Mn}, 4 \% \mathrm{Mo}$ and $0.9 \% \mathrm{~N}$ ).

\section{Properties}

Whilst the conventional $\mathrm{CrNi}$ steels exhibit yield strengths of below $300 \mathrm{MPa}$ in the solution-annealed state, the nitrogen austenites have more than double the strength at over $600 \mathrm{MPa}$. Figure 13 shows the influence

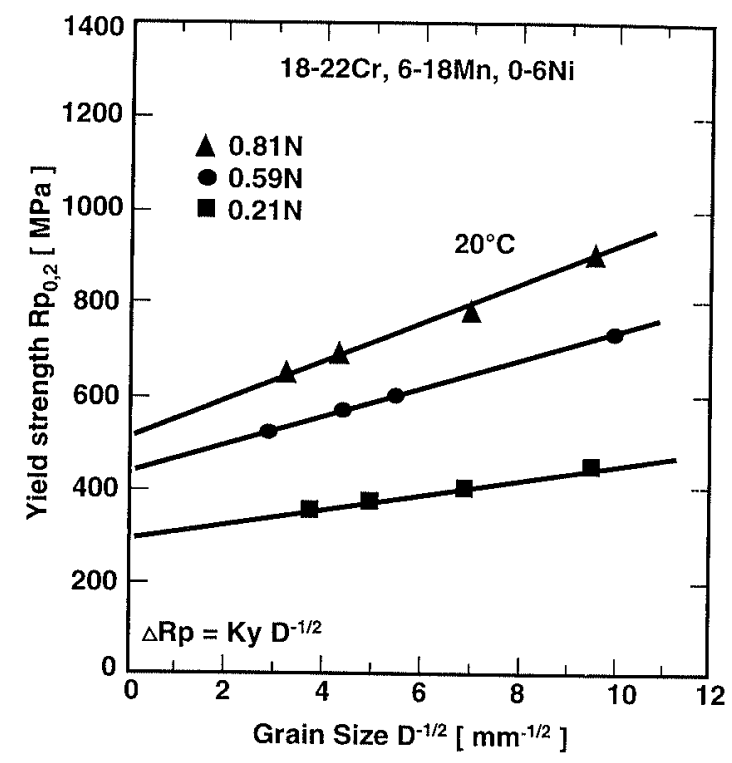

Fig. 14. Influence of nitrogen on the Hall-Petch-Equation.

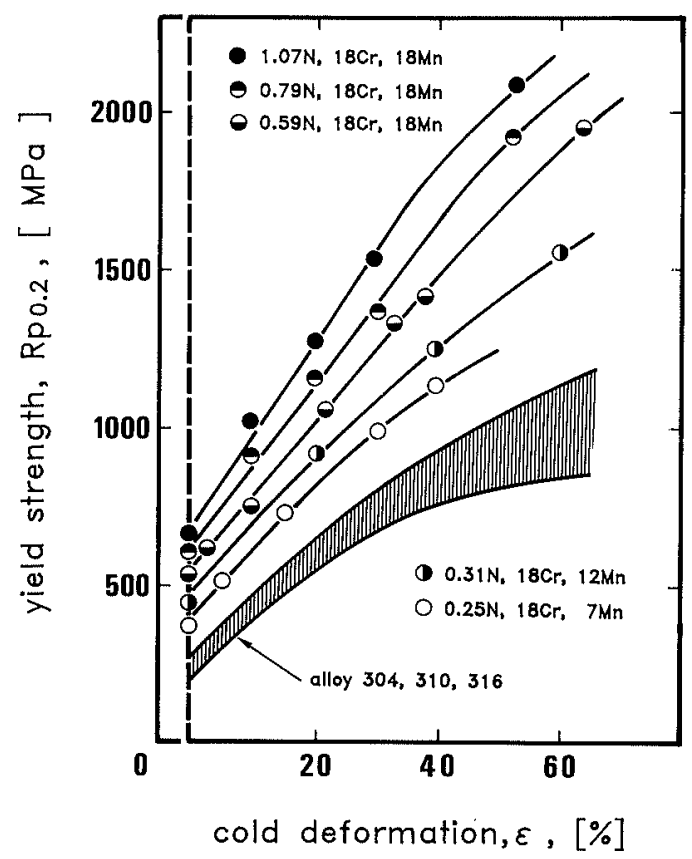

Fig. 15. Effect of the $\mathrm{N}$ in solid solution after cold deformation.

of the nitrogen content on the strength of austenites under the condition that the nitrogen is present in interstitially dissolved form. The influence of the nitrogen on yield strength can be estimated by means of the modified Hall-Petch equation. It becomes clear that the nitrogen influences not only the frictional stress $\sigma_{j}$ but also the grain boundary resistance $k_{\mathrm{y}}$. This relationship is shown in Fig. 14. In the nitrogen austenites the increase in strength is associated with an increase in toughness - $A_{\mathrm{v}}$ values of more than $300 \mathrm{~J}$ are attained (determined on ISO-V-specimens).

As well as the increase in strength in the solutionannealed state the nitrogen also has a positive effect on cold-formability (Fig. 15). Whilst with the conventional $\mathrm{CrNi}$ steels the cold forming curves reach saturation point at a maximum $1300 \mathrm{MPa}$ (shaded area), the nitrogen- 


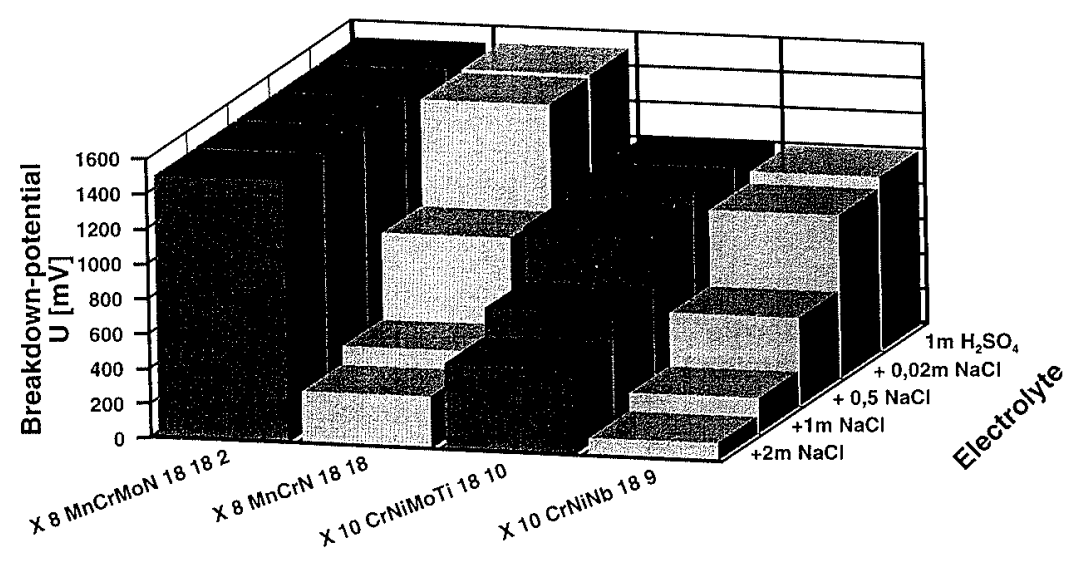

Fig. 16.

Breakdown-potential of different austenitic steels in $\mathrm{H}_{2} \mathrm{SO}_{4}$-solution with increasing $\mathrm{Cl}^{-}$-contents.

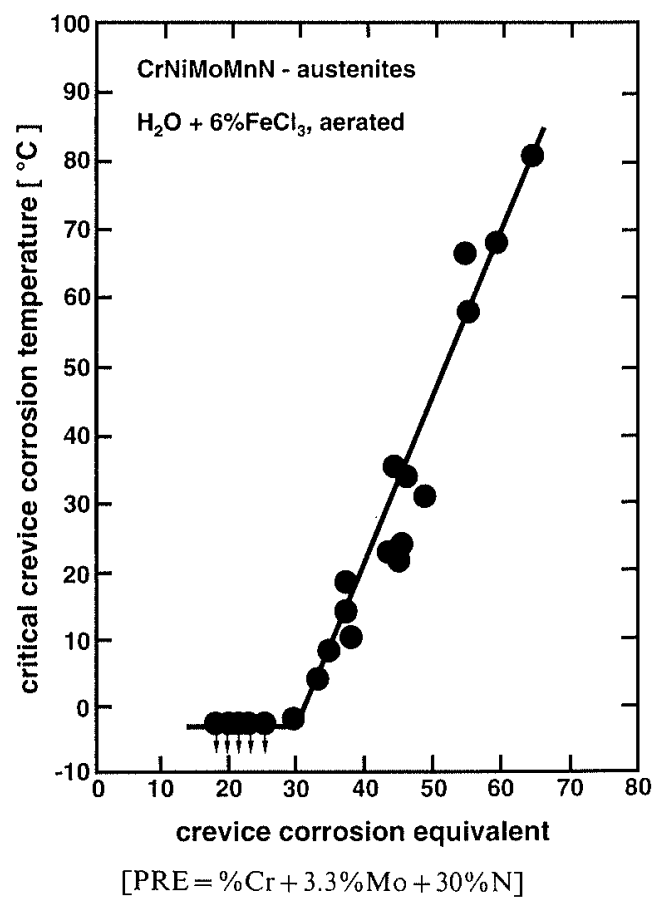

Fig. 17. Improvement in corrosion resistance, linked to the increase in chromium, molybdenum and especially nitrogen content.

alloyed $18 / 18 \mathrm{CrMn}$ steels permit yield strengths of up to $2500 \mathrm{MPa}$.

Of particular significance for the use of metallic materials which are to come into contact with the human body is corrosion resistance. High corrosion resistance ensures that the release of harmful metal ions is minimalized and that material breakage caused by local corrosion is prevented. Figure $\mathbf{1 6}$ shows the breakdown potentials of the nitrogen-alloyed $18 / 18 \mathrm{CrMn}$ steels compared with a number of conventional $18 / 10 \mathrm{CrNi}$ steels. It can be clearly seen that even the alloying variant with $\mathrm{N}$ and Mo contents of as little as 0.8 and $2 \%$, respectively, exhibits a previously unattained breakdown potential of approx. $1500 \mathrm{mV}$, even under extreme stress in $2 \mathrm{~m} \mathrm{NaCl}$ solution. The high corrosion resistance is attributable in particular to the effect of the nitrogen, which in conjunction with the elements chromium and molybdenum achieves 20 to 30 times the effect of chromium. Accordingly the formula for combatting pitting and crevice corrosion is

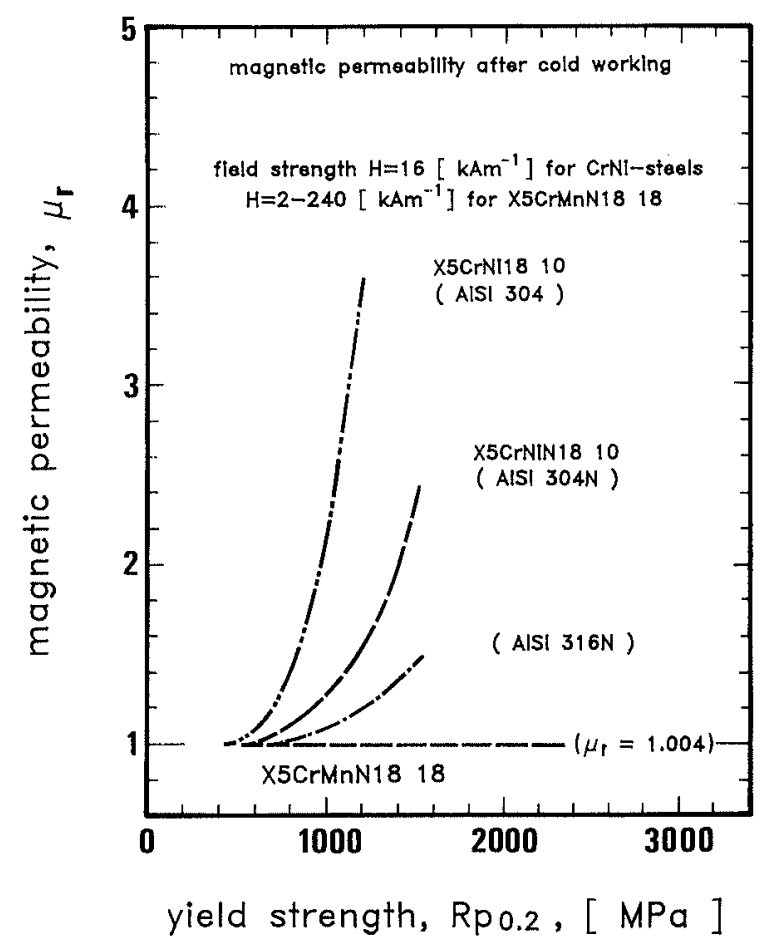

Fig. 18. Magnetic permeability after cold working.

$$
\mathrm{PRE} \cong \% \mathrm{Cr}+3.3 \% \mathrm{Mo}+25 \% \mathrm{~N}
$$

The formulae for the nitrogen austenites are thus around 50 , whilst even molybdenum-alloyed $18 / 10 \mathrm{CrNi}$ steels scarcely reach 30 . Thus, in aerated $6 \%$ iron-III-chloride solution critical crevice corrosion temperatures of approx. $50^{\circ} \mathrm{C}$ derive for the nitrogen austenites whilst the temperatures for the $18 / 10$ austenites are below $0^{\circ} \mathrm{C}$ (Fig. 17).

A further characteristic property of the $18 \mathrm{Cr} / 18 \mathrm{Mn}$ austenites is their extremely low magnetisability. This is attributable to the strong austenite-stabilizing effect of the nitrogen, which prevents martensite from forming, even under the toughest cold-forming conditions or cryogenic cooling. The value for the magnetic permeability remains constant throughout at $\mu_{\mathrm{r}}=1.004$ (Fig. 18).

By adapting the composition of the alloy to the respective application the prospect exists of substituting both conventional $\mathrm{CrNi}$ steels and $\mathrm{Ti}$ and $\mathrm{Co}$ special alloys in virtually all areas of application. 


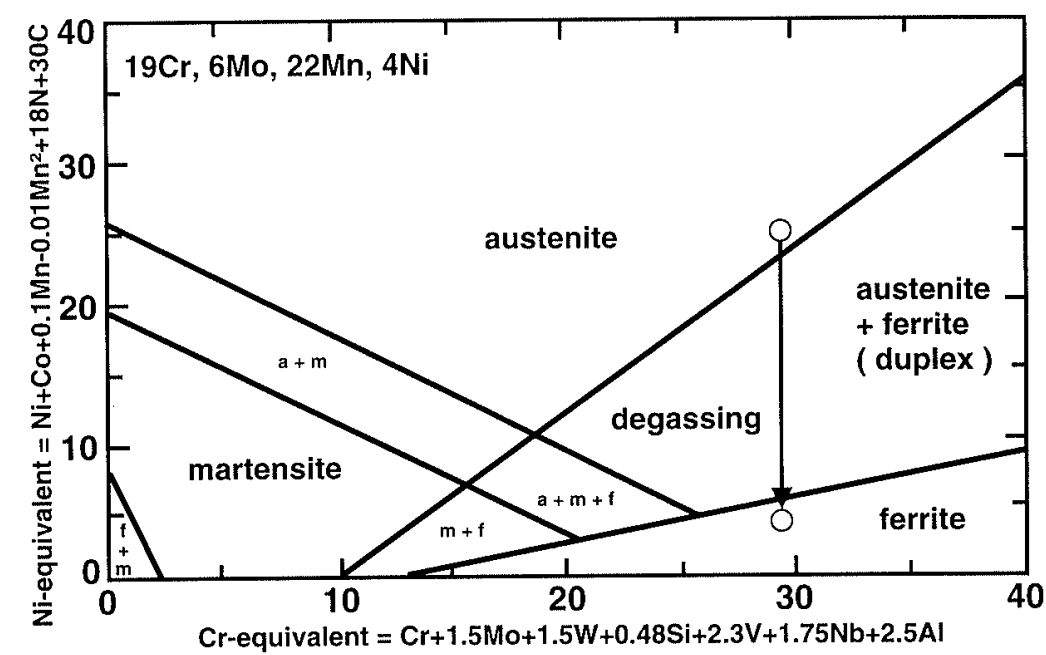

Fig. 19.

Influence on microstructure after degassing.

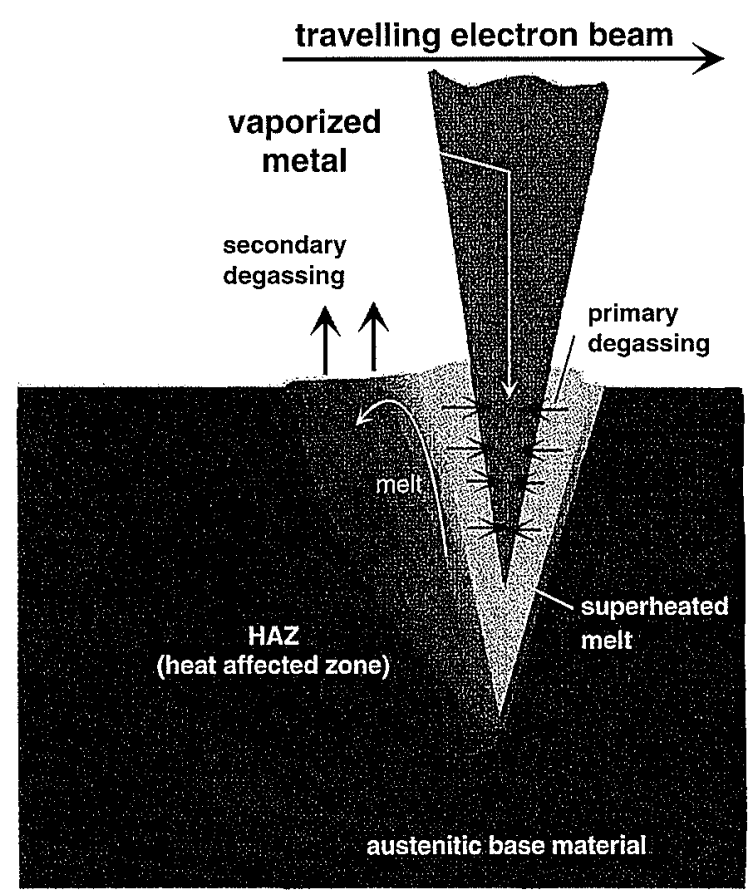

Fig. 20. Degassing situation during electron beam remelting.

\section{Applications}

The great economic significance of the new alloys becomes evident when one considers the broad area of applications which involve the human body coming into contact with metallic materials and in which nickel is thus undesirable. The range extends from fashion jewellery through applications in the clothing industry, spectacle frames, wristwatch casings and other metallic objects worn next to the skin, to surgical and dental applications such as medical instruments, applications and needles, temporary and permanent implants for dental correction and for stabilizing bone fractures.

A special application as a structural material suggests itself for these alloys on account of their extremely low magnetizability and the dependence of the magnetizability on the $\mathrm{N}$ content (Fig. 19 austenite/ferrite ratio). Amagnetic behaviour is a prerequisite for instruments which are used, for example, for examinations in strong magnetic fields (nuclear spin tomography). Magnetizable materials lead to major distortion of the graphic representation (irradiation) whilst amagnetic materials are represented with very little contrast. Through targeted treatment of the amagnetic instrument surface with laser or electron beams, which leads to local nitrogen leakage and thus to the conversion of austenite into ferrite, all representations of the contrast are possible (Fig. 20).

\section{REFERENCES}

1) Information of the German Industrial Employees' Accident Insurance Association.

2) G. Stein and J. Lueg: Proc. of 3rd Int. Conf. on High Nitrogen Steels, Kiev, (1993), 31.

3) P. J. Uggowitzer and M. Harzenmoser: Proc. of 1st Int. Conf. on High Nitrogen Steels, Lille, (1988), 174.

4) H. Feichtinger et al.: Proc. a.m. Conf., 75.

5) G. Stein, J. Menzel and H. Dörr: Proc. a.m. Conf., 32.

6) P. J. Uggowitzer and M. O. Speidel: Proc. of 2 nd Int. Conf. on High Nitrogen Steels, Aachen, (1990), 156. 